\title{
DIREITOS SOCIAIS E IDENTIDADE OPERÁRIA: O PODER DA IDEOLOGIA TRABALHISTA NO GOVERNO DE GETÚLIO VARGAS (BRASIL, 1930-45)
}

\section{SOCIAL RIGHTS AND WORKER IDENTITY: THE POWER OF IDEOLOGY IN LABOR GETÚLIO VARGAS GOVERNMENT (BRAZIL, 1930-45)}

\author{
Carlos Eduardo França \\ Doutor em Ciências Sociais pela UNESP. \\ Professor do curso de Ciências Sociais da Universidade Estadual de Mato Grosso do Sul (UEMS) e \\ Professor do quadro permanente do Programa de mestrado em Educação da UEMS (Paranaiba/MS). \\ carloseduardo@uems.br \\ RAFAEL LAMERA CABRAL \\ Doutor em Direito, Estado e Constituicão pela Universidade de Brasília (UnB). \\ Professor do curso de Direito da Universidade Federal Rural do Semi-árido (UFERSA), em Mossoró-RN. \\ rafaelcabral@ufersa.edu.br
}

\begin{abstract}
RESUMO
O objetivo deste trabalho é apresentar como na primeira metade do século XX, no Brasil, as discussões políticas e as pressões sociais pela busca de direitos, associadas ao projeto político de Getúlio Vargas (no período de 1930, após a Revolução, até 1945), construíram a identidade de classe dos trabalhadores brasileiros. Na literatura nacional, o período é um marco para a construção da ideologia trabalhista nacional. A partir do momento em que o Estado converte sua estrutura agrário-exportadora para a fase industrial, mudanças nas instituições políticas, na economia e na construção da narrativa jurídica tornam-se fundamentais para a compreensão do período histórico. Parte dessas narrativas são revisitadas e confrontadas a partir da análise de fontes primárias produzidas no âmbito do Conselho Nacional do Trabalho e nos debates parlamentares na Assembleia Nacional Constituinte de 1933-34.
\end{abstract}

Palavras-chave: Direito do trabalho; Era Vargas; Identidade de classe; Ideologia trabalhista; Política nacional brasileira.

\begin{abstract}
The aim of this paper is to present how, in the first half of the twentieth century in Brazil, political discussions and social pressure to pursue rights, associated with the political project of Getúlio Vargas (from 1930, after the Revolution, to 1945) built the class identity of Brazilian workers. The national literature shows that the period is a milestone for the construction of the national labor ideology. From the moment that the State modified its agrarian and exportation structure to the industrial one, the changes in policies, economy and the construction of the legal narrative are fundamental to understand this historical period. Some of these narratives are revisited and confronted from an analysis of primary sources produced in the context of the National Labor Council and in the parliamentary debates in the Brazilian Constituent Assembly of 1933-34.
\end{abstract}

Keywords: Labor law; Vargas Age; class identity; Labor ideology; Brazilian national policy. 


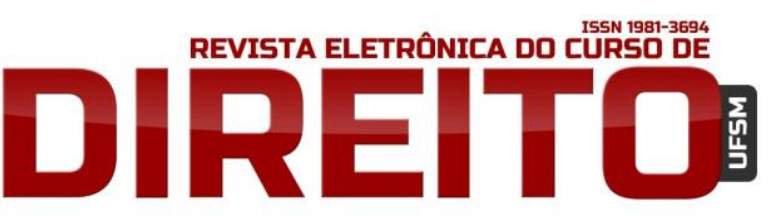

DIREITOS SOCIAIS E IDENTIDADE OPERÁRIA: O PODER DA IDEOLOGIA TRABALHISTA NO GOVERNO DE GETÚLIO VARGAS (BRASIL, 1930-45)

\section{SUMÁRIO}

INTRODUÇAO; 1 DIREITOS SOCIAIS, CLASSE TRABALHADORA E A TUTELA DOS SUJEITOS HISTÓRICOS NO ESTADO DE DIREITO (1930-45); CONCLUSÃO; REFERÊNCIAS.

\section{INTRODUÇÃO}

O presente trabalho tem como eixo central a discussão política das pressões sociais pela busca de direitos, associado ao projeto político de Getúlio Vargas no Brasil de 1930 a 1945 que, por meio de diversas ações, construiu a identidade de classe dos trabalhadores ao tecer os elementos sócio-históricos e culturais que culminaram na elaboração da ideologia trabalhista.

Para tanto, inicia-se a discussão sobre a história política constitucional brasileira à codificação dos direitos do homem, para constatar que esses princípios legalistas dos direitos humanos no Brasil sempre foram objeto de constantes tensões que suscitaram mitos e dilemas em sua própria construção histórica. Primeiro, passa-se pela fase do reconhecimento de direitos humanos e, em seguida, para a constante crise por sua efetivação.

Os direitos humanos introduzem nos ordenamentos jurídicos uma classe especial de direitos subjetivos. Decorrente de uma construção histórica, os direitos subjetivos são considerados como a faculdade dada por normas de ordem pública (a lei) para que o cidadão possa buscar a reparação de um direito violado ou, ainda, oportunizar instrumentos de defesa a um direito passível de violação.

Neste sentido, muitas classes de direitos subjetivos podem coexistir em um mesmo ordenamento jurídico, sem qualquer relação de prejudicialidade. Porém, um imperativo torna-se fundamental para a compreensão de determinadas classes de direitos: o que faz de um direito ser dotado de caráter fundamental? A esta pergunta, muitas respostas podem ser encontradas. A princípio, fundamentando em Pulido, ${ }^{1}$ o caráter básico dos direitos fundamentais consiste em um conjunto de propriedades formais (reconhecidas em capítulos específicos de direitos fundamentais previstos nas Constituições ou aquelas reconhecidas pela jurisprudência constitucional) e propriedades materiais (dimensão liberal, democrática ou social dos direitos fundamentais).

Historicamente, a constitucionalização de direitos humanos passou por uma progressiva ampliação que se iniciou nos direitos civis, avançou para os direitos políticos e se concluiu nos

\footnotetext{
${ }^{1}$ PULIDO, Carlos Bernal. 0 caráter fundamental dos direitos fundamentais. Revista de Direito do Estado.
} 
direitos sociais. Nesta linhagem, as análises de Marshall ${ }^{2}$ são as principais referências. No entanto, esta sequência histórica de constitucionalização não aconteceu no Brasil, como destaca Carvalho ${ }^{3}$ e Bercovici. ${ }^{4}$ No Brasil, muitos avanços constitucionais por meio da efetivação de direitos foram paralelas à construção de uma cidadania de caráter restritiva, de baixa intensidade e representatividade, e com um poder ideológico organizado por setores políticoeconômicos que limitaram a construção do esquadro de nossa modernidade.

Os direitos de cidadania são entendidos por Marshall ${ }^{5}$ como correspondentes a uma tríade específica compreendida na conjunção de direitos civis (representados pelas liberdades individuais de cada ser humano), direitos políticos (aglutinados na capacidade de oportunizar a participação política de se representar e ser representante, mediante escolha de candidatos dentro de um processo eleitoral), e direitos sociais (que correspondem ao direito de trabalho, educação, saúde, desporto e lazer, dentre outros).

Decorrente do caráter fundamental que essas dimensões dos direitos representam para o desenvolvimento de um país nos campos político, econômico e social, o fio condutor da pesquisa parte da compreensão de como a ideologia de Estado na década de 1930 comprometeu o desenvolvimento da construção da cidadania brasileira, devido articulações políticas, estatais e empresariais que, com uma sagacidade impar, conseguiu construir um projeto políticoideológico: a ideologia trabalhista. Este projeto foi o responsável por organizar esforços de convencimento da classe trabalhadora de que os elementos discursivos contidos no governo Vargas correspondessem aos seus interesses enquanto identidade de classe; em um momento de extrema relevância para a construção do Estado-Nação brasileiro.

Deste modo, para que seja possível atingir o objetivo, a pesquisa buscou em fontes primárias os elementos necessários para a produção de uma interpretação do fenômeno trabalhista nos anos 1930. Essas fontes, disponíveis nos arquivos do Tribunal Superior do Trabalho e do Congresso Nacional, correspondem aos documentos e processos administrativos trabalhistas produzidos pelo Conselho Nacional do Trabalho ${ }^{6}$ entre 1923-1945 e aos debates

\footnotetext{
${ }^{2}$ MARSHALL, Thomas Humphrey. Cidadania, classe social e status. Rio de Janeiro: Zahar, 1967.

3 CARVALHO, José Murilo. Cidadania no Brasil: o longo caminho. 10. ed. Rio de Janeiro: Civilização Brasileira, 2008.

${ }^{4}$ BERCOVICl, Gilberto. Constituição e política: uma relação difícil. Lua Nova, São Paulo, n. 61, $2004 b$.

${ }^{5}$ MARSHALL, Thomas Humphrey. Cidadania, classe social e status. Rio de Janeiro: Zahar, 1967, p. 4.

60 Conselho Nacional do Trabalho foi criado em $1923 \mathrm{com}$ a finalidade de produzir estudos sobre a organização do trabalho e previdência social, em auxílio direito ao Estado brasileiro. Ressignificado desde sua criação, o conselho se transformou em Tribunal Superior do Trabalho após ampla reforma em 1939, oportunidade em que foi completamente incorporado à Justiça do Trabalho posteriormente.
} 
constituintes no âmbito da Assembleia Nacional Constituinte de 1933-34. Em um segundo momento, as produções bibliográficas sobre o período foram revisitadas, a fim de ampliar os debates sobre o tema "trabalho" a partir da década de 1930.

0 texto foi organizado e dividido em duas partes: na primeira, analisa-se o contexto sócio-político da Primeira República para o pós-Revolução de 1930 em relação aos direitos sociais de cidadania e, por fim, observa-se como a classe trabalhadora, ao se constituir enquanto ator político central na política brasileira, contribuiu para o reconhecimento dos direitos sociais como atributo de direito humano fundamental, ao ser tutelado e promovido pelo Estado de Direito.

\section{DIREITOS SOCIAIS, CLASSE TRABALHADORA E A TUTELA DOS SUJEITOS HISTÓRICOS NO ESTADO DE DIREITO (1930-45)}

A rigor, uma das principais características dos Estados-Nação era a organização do poder atrelada ao reconhecimento de direitos de cidadania, capazes de exercer limites institucionais ao poder soberano. Em um plano amplo, esses direitos permitiriam a oportuna participação efetiva das várias camadas da população nas principais tomadas decisórias. ${ }^{7}$ No entanto, essas características que tipificam o Estado-Nação ideal foram, em grande parte, afugentadas do processo de formação republicana brasileira (1889-1930).

Esses direitos de cidadania foram incorporados na Primeira República de uma forma muito singular. ${ }^{8} \mathrm{O}$ desenvolvimento inicial dos direitos civis (representados pela manutenção das liberdades de ir e vir e de não ser processado ou julgado sem o devido processo legal, entre outros), acabava por limitar os direitos políticos restritos no início da Primeira República. 0 direito ao voto, por exemplo, não atingia sequer três por cento da população adulta e seu exercício não se subordinava aos efeitos do voto secreto (ato incrementado na República apenas em 1932).

A Constituição de 1891 não inseriu os direitos sociais em suas disposições por não se constituir uma demanda consolidada que se configurasse em representação política. Aliás, havia, na verdade, o peso de um sistema social que refletia os efeitos da herança colonial escravista.

\footnotetext{
${ }^{7}$ BENDIX, Reinhard. Construção Nacional e Cidadania. São Paulo: Edusp, 1996.

${ }^{8}$ CARVALHO, José Murilo. Cidadania no Brasil: o longo caminho. 10. ed. Rio de Janeiro: Civilização Brasileira, 2008.
} 
Com direitos civis e políticos limitados a uma pequena parcela da população desde o final da década de 1910, uma onda de reivindicações sobre as melhorias de condições nas vidas dos trabalhadores ganharam expressão de forma mais intensa.

A questão social começava a se formalizar como agenda política através das organizações dos movimentos operários e anarquistas. ${ }^{9}$ Com a greve geral de julho de 1917, em São Paulo, essas manifestações começavam a se tornar cada vez mais frequentes, e algumas ações governamentais entravam em vigor, como exemplo a Comissão Especial de Legislação Social criada no âmbito da Câmara dos Deputados. ${ }^{10}$

Essas mudanças sócio-culturais e econômicas, principalmente ao proporcionar à sociedade urbana uma projeção no quadro econômico, social e político do país, acabaram por implementar uma reestruturação no avanço dos direitos sociais em relação ao trabalho. As tímidas manifestações desses avanços aconteceram em 1917, com a reforma do Código Sanitário, buscando melhorar as condições de trabalho de mulheres e menores nos diversos setores das atividades urbanas.

Em 1919, o Governo Federal sancionou a primeira lei dispondo sobre as obrigações patronais resultantes de acidentes no trabalho; em 1923, com a criação do Conselho Nacional do Trabalho (reorganizado em 1928); e em 1927, com o estabelecimento das leis de assistência e proteção aos menores. ${ }^{11}$

No entanto, durante a Primeira República, e em relação aos direitos sociais, observouse que as principais inovações ocorriam em relação aos direitos trabalhistas sem uma evidenciação ampla sobre as demandas sociais à educação pública e obrigatória às crianças e, até mesmo, pela ampliação do sistema de saúde (presente, com dificuldades, apenas nos grandes centros urbanos).

Com a Revolução de 1930, os direitos de cidadania seriam objeto de extensões e redefinições que refletiram, na promulgação de inúmeros decretos governamentais, uma origem complexa o suficiente para alimentar mitos sobre nossa trajetória política e jurídica sobre a história legislativa de nossas conquistas por novos direitos. É certo que, na década de 1930, seria a Constituição de 1934 a primeira a constitucionalizar direitos sociais, mas tal fato não permite consagrar a tese de que os direitos foram outorgados pelo governo em favor dos trabalhadores

\footnotetext{
${ }^{9}$ SIMÃO, Azis. Sindicato e Estado: suas relações na formação do proletariado de São Paulo. São Paulo: Ática, 1981.

${ }^{10}$ GOMES, Angela Maria de Castro. A invenção do trabalhismo. São Paulo: Vértice/IUPERJ, 1988.

11 SIMÃO, Azis. Sindicato e Estado: suas relações na formação do proletariado de São Paulo. São Paulo: Ática, 1981.
} 
ou que a modernização ocorrera de cima para baixo. Estudos recentes sob a perspectiva da história constitucional têm demonstrado como a organização dos trabalhadores foi fundamental para a construção de nossa identidade trabalhista e, por consequência, demonstrar as estratégias e ações legislativas que indexaram em nossa experiência constitucional de direitos inéditos como produto de um arranjo complexo. ${ }^{12}$

No início da década de 1930, essas questões foram elaboradas constitucionalmente em dois grandes movimentos: primeiro, pelo trabalho da subcomissão do Itamaraty $^{13}$ de 1932 , e, posteriormente, encontrariam respaldo no processo constituinte de 1933-34, principalmente por se estabelecerem em um momento de revisão, no qual as forças do moderno encaminhavam o Brasil para uma relação de modernização. ${ }^{14}$ É preciso sempre questionar o discurso sobre modernização/modernidade que marca grande parte dos estudos sobre a década de 1930 no Brasil.

Para que a modernização pudesse ser introduzida em uma comunidade política, ela não exigia que a sociedade fosse plenamente moderna. Era possível que a modernização ocorresse sem resultar em "modernidade”, já que coexistem em um mesmo tempo histórico rupturas e permanências decorrentes do processo de modernização.

Seguindo esta perspectiva analítica,

Onde quer que tenha ocorrido, a modernização das sociedades deu origem a estruturas sociais marcadas por desigualdades baseadas em laços de parentesco, privilégio hereditário e autoridade estabelecida. A destruição dessas características da velha ordem e o conseqüente surgimento da igualdade são marcas da modernização. ${ }^{15}$

A modernização das sociedades, nos termos evidenciados por Bendix, não se aplicava diretamente ao caso brasileiro. Essa ressalva se constitui pela característica do hibridismo das relações políticas, econômicas e sociais que afetava a relação entre tradição e modernidade, prejudicando o surgimento da igualdade entre os cidadãos, restringida pelo clientelismo político

\footnotetext{
12 Nesse sentido, ver GUERRA, Maria Pia. Anarquistas, trabalhadores, estrangeiros: a construção do constitucionalismo brasileiro na primeira República. Dissertação de mestrado em Direito. Brasília: UnB, 2012, e também em CABRAL, Rafael Lamera. Nos rastros de um processo: trabalho, conflito e uma experiência de micro-história. Tese de doutoramento em Direito. Brasília: UnB, 2016.

${ }^{13}$ A subcomissão do Itamaraty foi constituída por Getúlio Vargas para que uma equipe de juristas notáveis pudessem estabelecer um anteprojeto de constituição a ser apresentado pelo governo provisório à futura Assembleia Nacional Constituinte.

${ }^{14}$ CABRAL, Rafael Lamera. Constituição e sociedade: uma análise sobre a (re)formulação na arquitetura do Estado-Nação na Assembleia Nacional Constituinte de 1933. Dissertação de mestrado em Ciência Política. São Carlos: UFSCar, 2010.

${ }^{15}$ BENDIX, Reinhard. Construção Nacional e Cidadania. São Paulo: Edusp, 1996, p. 8.
} 
e formas de dominação que giram em torno da ideologia do favor que, como disse Sergio Buarque de Holanda, ${ }^{16}$ emperram o processo de desenvolvimento da racionalização das instituições democráticas brasileiras. Além disso, a relação brasileira, dentro desta transição, sempre se ancorou na relação mercantil-exportadora.

Algumas das características iniciais da modernização brasileira observadas neste trabalho se referem às transições entre o "desenvolvimento tradicional" para a "modernização" em vários arranjos que se destacavam na década de 1930.

Naquele período, uma transformação nos eixos econômicos, políticos e sociais estavam se formalizando. As demandas advindas das pressões dos movimentos sociais e operários desde a Primeira República tencionavam o Estado (direta e indiretamente), no sentido de influenciar uma reconstrução que fosse direcionada para a solução de conflitos e o estabelecimento de acordos.

$\mathrm{Na}$ ordem econômica, por exemplo, havia uma profunda transformação no sistema de acumulação de capital, em regra realizado pela transição da fase agrário-exportadora para uma dinâmica de industrialização que atendesse o mercado interno. Essa transição, em seu bojo, inseria na agenda política uma revisão e ampliação dos direitos de cidadania, especialmente relativos aos direitos trabalhistas e de assistência pública.

Politicamente, os mesmos direitos de cidadania também buscavam expansão para permitir uma ampliação no direito à participação política e, no período em análise, se constatava a criação da Justiça Eleitoral, o estabelecimento do direito ao voto secreto e a extensão do voto às mulheres ocorrido em 1932. No campo dos direitos sociais, temas como família, economia, assistência pública, saúde e educação também se inseriam dentro da agenda política em busca de concertação.

Entretanto, como ressalta Ângela de Castro Gomes, ${ }^{17}$ é com a classe trabalhadora inserida enquanto ator político central na política brasileira, a partir da década de 1930, que a questão da cidadania passa, no Brasil, pela questão dos direitos sociais.

Deste modo, a autora enfatiza que o problema da extensão da participação política e das diversas “cidadanias" que envolviam as culturas da classe trabalhadora desde a Primeira República serão reencontradas na conturbada reorganização social e política do período pós1930.

\footnotetext{
${ }^{16}$ HOLANDA, Sérgio Buarque de. Raízes do Brasil. São Paulo: José Olimpio, 1976.

${ }^{17}$ GOMES, Angela Maria de Castro. A invenção do trabalhismo. São Paulo: Vértice/IUPERJ, 1988.
} 
Para uma melhor compreensão deste processo de constituição da cidadania e consolidação dos direitos sociais no Brasil é necessário, primeiramente, revisitar as mobilizações sociais, as lutas dos trabalhadores e suas reivindicações históricas que culminaram nos pactos sociais existentes entre Estado e classe trabalhadora, bem como analisar como o Governo Vargas (1930-1945) conseguiu reler essas demandas sociais neste período, e captar os valores e tradições políticas brasileiras para articular a cultura e identidade de classe dos trabalhadores por meio da invenção do "trabalhismo" brasileiro enquanto ideologia.

Para Gomes ${ }^{18}$, a abolição da escravatura e Proclamação da República podem ser um bom ponto de partida para a compreensão desse fenômeno. Percebendo a correlação de forças existente entre os grupos que defendiam suas concepções de “cidadania”, bem como pela forma como reivindicavam para si uma maior visibilidade no sentido de se projetar como verdadeiro representante dos interesses e da identidade social coletiva da classe trabalhadora, a autora destaca que este processo de formação da classe operária como ator político passa, portanto, pela questão da construção do conceito de cidadania, e pela extensão dessa cidadania aos setores populares.

No Brasil, foi basicamente a partir dos anos do pós-1930, especialmente no período do Estado Novo, que a classe trabalhadora foi incorporada ao cenário da política nacional como ator central.

O acesso à cidadania assumiu no Brasil contornos bem significativos, definindo-se pela abstenção por parte dos trabalhadores do gozo de direitos políticos e dos direitos civis, caracterizando-se pela “cidadania regulada” pelo Estado. Esta se fundamentava na inserção profissional no mundo da produção, e na expansão de alguns direitos sociais sancionados por lei e garantidos pela carteira de trabalho.

É nesta concepção de democracia e “cidadania regulada” elaborada no Governo Vargas (1930-1945), que se estruturou o projeto político implementado pelo Estado, chamado por Castro Gomes ${ }^{19}$ de "trabalhismo" brasileiro.

Este projeto consagrou a eficácia da “ideologia trabalhista" por meio de várias formas de afirmação e instrumentos de comunicação, rememorando valores antigos dos trabalhadores, ressignificando-os e adaptando-os ao projeto político do Estado Novo, ao mesmo tempo em que cultuava a figura de Getúlio Vargas.

\footnotetext{
${ }^{18}$ GOMES, Angela Maria de Castro. A invenção do trabalhismo. São Paulo: Vértice/IUPERJ, 1988. ${ }^{19}$ Ibid.
} 
Uma das táticas importantes para a divulgação desta nova ideologia política foi a produção e emissão de um discurso político direcionado a um público bem específico. Este discurso político tinha como ator principal o ministro Alexandre Marcondes Filho, que com suas intervenções constantes no programa radiofônico Hora do Brasil, difundia o projeto político do Estado brasileiro do pós-1942.

A ideologia trabalhista teve extensão e apoios nas políticas públicas desenvolvidas por vários ministérios de Vargas, como os da saúde, da educação, alimentação e do lazer, que contribuíram na afirmação das intenções do discurso governamental.

Este processo, portanto, possui dois momentos principais. O primeiro deles é lento e toma as décadas da Primeira República, onde as propostas políticas, pequenas lutas e a "palavra operária” vinculavam-se às lideranças da própria classe trabalhadora que, indiscutivelmente, assumem a construção de propostas sobre a sua identidade de classe.

A aspiração pela constituição desta identidade de classe girou em torno da valorização de um modelo de trabalhador, apresentado nos discursos como trabalhador livre e educado no “culto ao trabalho". Neste processo, cria-se a valorização de uma determinada figura do trabalhador. Esse estágio foi construído passo a passo desde a criação do Ministério do Trabalho, Indústria e Comércio, em 1930, acompanhados de uma renovação institucional na lei de sindicalização, nacionalização do trabalho (lei dos 2/3), fixação de jornada de trabalho, introdução das carteiras de trabalho e inúmeros decretos regulamentando múltiplas profissões.

O segundo momento está marcado pela atuação do Estado Novo que, em um primeiro movimento (1930-1937), investiu na desmobilização da classe trabalhadora sob o comando do Ministro do Trabalho Agamenon Magalhães. A desmobilização das organizações de classe foi vista como necessária pelo Estado devido ao clima político em 1934 ter sido marcado pela significativa radicalização ideológica e de crescente mobilização das massas. Em parte, a radicalização correspondia aos grandes movimentos que impulsionaram a criação da Aliança Nacional Libertadora, Lei de Segurança Nacional, em abril de 1935, e a intentona comunista, em novembro do mesmo ano.

As articulações mais intensas eram as do Partido Comunista que, atrelado à parte do movimento sindical sob a orientação de lideranças de esquerda, tinha como objetivo organizar uma linha de frente popular. As lideranças do Partido Comunista historicamente atuantes junto à classe trabalhadora brasileira foram, no projeto político organizado pelo Governo Vargas (19301945), fortemente neutralizadas pelo braço armado do Estado varguista e pelo conjunto de 
ações políticas e ideológicas que incidiram nas instituições da classe trabalhadora, em prol da construção da "cidadania regulada" presente no trabalhismo brasileiro construído por Vargas.

Nesses termos,

\begin{abstract}
Somava-se ainda a este imbróglio, o agravamento das tensões inerentes ao processo de modernização econômica e política e o surgimento de um quadro de convulsão e conflito nunca antes presenciado na história nacional. Não eram apenas as oligarquias que se movimentavam, pela inclusão no pacto de poder ou reversão deste ao seu anterior controle; era uma variação de atores e frações que emergiam no bojo da modernização em curso, disputando espaço e representação. Novos interesses ligados ao capital - setor mercado externo (agrário-exportador) versus setor mercado interno (industrial e diversificado); disputas entre os vários segmentos do capital comercial, industrial; latifúndio agro-exportador versus minifúndio voltado ao abastecimento do mercado interno em expansão. Do lado do trabalho, cenário igual se reproduzia já que os trabalhadores eram incorporados a processos muito desiguais de contratação e remuneração, além de estarem ligados a um ou outro dos setores produtivos acima apontados. Ainda são importantes no período os setores urbanos de classe média, o funcionalismo público, as profissões liberais, afora as desigualdades regionais. ${ }^{20}$
\end{abstract}

Com o agravamento das tensões acima descritas, os primeiros anos do Governo Vargas (1930 - 1934) foram destinados à neutralização destas forças sociais em ebulição (e para tanto, os expedientes utilizados se instrumentalizavam pela suspensão do Estado de Direito e, em alguns casos, na coerção propriamente dita, principalmente ao tolher o direito da livre manifestação do pensamento com censura aos jornais). Nesse aspecto, o Estado atingiria grande parte de seus objetivos iniciais.

A título de ilustração, pôde-se notar que as oligarquias, ao se movimentarem em seus blocos regionais, sempre encontravam a atuação direta dos interventores federais nos Estados, o que, a princípio, já poderia ser um forte indício dessa estratégia de neutralização. Quando esses interventores demonstravam alguma espécie de comprometimento com as oligarquias regionais e eram pressionados por elas, o chefe do Governo Provisório promovia a alteração, restabelecendo a negociação, a cooptação e a resolução do conflito. ${ }^{21}$ Com o Estado Novo, esse controle sobre os Estados ressurgem em torno de um único líder: o presidente Getúlio Vargas.

${ }^{20}$ CEPÊDA, Vera Alves. Contexto político e a crítica a democracia liberal: a proposta de representação classista na Constituinte de 1934. In: MOTA, Carlos Guilherme; SALINAS, Natasha S. C. Os juristas na formação do Estado-nação brasileiro. São Paulo: Saraiva, 2010, p. 199.

${ }^{21}$ GOMES, Angela Maria de Castro. Confronto e compromisso no processo de Constitucionalização (19301935). In: FAUSTO, Bóris. História Geral da Civilização Brasileira. Tomo III: O Brasil Republicano. São Paulo: Difel, 1990. 
Os atores que se destacavam e que também emergiam dos fatores de modernização, tornando-se potenciais opositores as políticas empregadas pelo Governo Vargas, também eram aliciados pelo poder central provisório. Esses atores recebiam contraofertas para juntar-se ao grupo de apoio governamental, ou recebiam punições/restrições, ${ }^{22}$ ou eram "silenciados" devido a forte restrição à manifestação do pensamento, principalmente quando críticas eram estabelecidas contra o governo pela imprensa.

Nos próprios debates na Constituinte (1933-34) observavam-se as manifestações dos congressistas pugnando pelo restabelecimento da livre manifestação do pensamento, condenando a forma arbitrária pela qual o governo agia contra os jornais.

Aspectos de grande relevância também ocorreram no campo relacionado aos conflitos entre capital e trabalho e o Governo Vargas. Estando este no foco da crise, a elaboração de um pacto de intervenção direcionado a não deflagração do conflito acabava por se tornar um importante tópico na agenda política do período. A regulação entre capital e trabalho realizada pelo Governo seria compreendida como um dos principais marcos do processo de modernização instaurado pela nova ordem constitucional e institucional do país.

A regulação fora estabelecida com o objetivo de atenuar as divergências entre os setores urbanos, pacificando os ânimos entre empregadores e empregados em conflito acentuado desde a década de 1910. A regulação seria uma saída para que o segmento industrialista pudesse ter controle sobre o processo produtivo. Ao mesmo tempo, a regulação, ao criar parâmetros para serem acatados pelos empregadores, oportunizava espaço para a intervenção mais direta dos sindicatos em todo processo de negociação. ${ }^{23}$

Com o desenvolvimento dos sindicatos

[...] também exemplifica o movimento dos direitos civis que vai da representação de indivíduos para a de comunidades. Essa representação coletiva dos interesses econômicos dos membros surge da inabilidade dos trabalhadores de salvaguardar seus interesses individualmente. [...] Esses resultados práticos

\footnotetext{
${ }^{22}$ Nos debates constituintes da ANC os deputados acabariam por estabelecer inúmeros apelos no sentido que o Governo provisório estabelecesse a anistia aos exilados políticos desde a Revolução de 30.

${ }_{23}$ Para uma análise da evolução das associações sindicais presentes no Estado de São Paulo (onde as principais manifestações grevistas aconteceram no início do Século XX) ver Azis Simão. Sindicato e Estado: suas relações na formação do proletariado de São Paulo. São Paulo: Ática, 1981, p. 99. Simão afirmava que entre 1901 e 1914 houve 81 registros de greves referentes à capital paulista e 38 em várias cidades menores, sendo que um quadro relativo a conflitos de certa amplitude, incluindo estabelecimentos de um mesmo ou de vários setores econômicos [...]. Entre 1915 e 1929, na Capital, anotaram-se 42 conflitos em estabelecimentos isolados, 20 em setores econômicos e 2 inter-profissionais, 1 generalizado e 1 geral.
} 
dos sindicatos têm um efeito de longo alcance na posição dos trabalhadores como cidadãos. ${ }^{24}$

Os sindicatos exerciam uma posição especial por permitir aos trabalhadores a possibilidade de se organizarem e terem voz, mesmo em um contexto repleto de incertezas e poucos avanços. Ainda assim a regulação, de certa forma, também representava a estratégia de manutenção da estrutura conservadora agrária, posto que os trabalhadores rurais não experimentaram uma regulação propriamente dita, continuando à margem do projeto de regulação. ${ }^{25} \mathrm{~A}$ regulação também representou uma maneira sistemática de legitimação do Estado, visto que o expediente utilizado pôde ser contabilizado como meio fim em busca da resolução dos conflitos sociais potencializados entre o operariado e o empresariado.

O fato foi que a proposta de regulamentação do setor, apresentada pelo Governo Vargas via constitucionalismo social, ${ }^{26}$ ocorreu em um momento em que a incipiente industrialização da sociedade (decorrente da modernização tardia do país) e a consequente ampliação e mudança do mercado de trabalho (de agrário para industrial) reclamava uma nova postura do poder público.

A ação do governo gerou o acolhimento de "um programa de legislação social, onde o Estado 'protetor', absorvendo os intentos societários e incorporando a 'questão social', define a estratégia do 'compromisso' nas relações entre o capital e o trabalho". ${ }^{27}$

A pactuação da estratégia de solução de compromisso nas relações entre esses setores expressava a singularidade brasileira quando o tema era a questão social. Esta, que naquela época se constituía pelo aparecimento de novos atores, péssimas condições de vida e pela deterioração da sociabilidade urbana, moldava um ator social (na maioria, representado por

\footnotetext{
${ }^{24}$ BENDIX, Reinhard. Construção Nacional e Cidadania. São Paulo: Edusp, 1996, p. 120.

${ }^{25}$ A regulação do trabalho no campo foi objeto de uma inclusão especial no texto constitucional de 1934 e que não se efetivara nos anos seguintes.

${ }^{26}$ É o formato jurídico onde há a constitucionalização das normas de direitos sociais. No contexto brasileiro o constitucionalismo social foi introduzido com a Constituição da República de 1934 quando reconhece, amplia e protege as normas de direitos sociais e econômicos aos trabalhadores e à família, ampliando assim as dimensões da democracia social.

${ }^{27}$ WOLKMER, Antônio Carlos. Constitucionalismo e direitos sociais no Brasil. São Paulo: Acadêmica, 1989, p. 24. A tese sobre o compromisso pactuado na ANC de 1933-34 pode ser observado nos trabalhos de Ângela Maria de Castro Gomes, intitulados "Regionalismo e Centralização Política: partidos e constituinte nos anos 30" e "Confronto e compromisso no processo de Constitucionalização (1930-1935)".
} 
trabalhadores urbanos) que, embora não pudessem ser idealizados como classe social, ${ }^{28}$ já articulava uma consciência de classe pronta para se manifestar.

No entanto, as manifestações operárias foram controladas/sufocadas durante todo o período pós-revolução (1930). Com a criação do Ministério do Trabalho, em 1930, o modelo de sindicalização implantado no país impôs limitações à autonomia sindical e, nesse contingente, as ações dos sindicalistas eram controladas e supervisionadas pelo Governo.

Os sindicatos só se constituíam com representatividade dos trabalhadores após aprovação e prévio cadastro no Ministério do Trabalho, entidade esta que prescrevia inúmeros requisitos para a organização dos trabalhadores em organizações sindicais. Com esta exigência do Estado que impactou na perda da autonomia sindical, os sindicatos ficavam na dependência das ações estatais, e poderiam, inclusive, perder seu registro caso cometessem atos considerados ilegais (atos estes analisados na esfera administrativa e não judicial).

No mesmo sentido, os trabalhadores também passaram por uma reestruturação nas carreiras, oportunidade em que a cidadania se estendia somente àquelas profissões classificadas pelo Ministério mediante assinatura da Carteira de Trabalho e Previdência Social - CTPS, instrumento criado no governo Vargas e que vigora até os dias atuais.

As investidas do Governo para a regulamentação do trabalho no Brasil tiveram também decorrência das influências internacionais. Durante a transição do século XIX para o XX, a questão social - o trabalho já era matéria de debate nas sociedades mais industrializadas (Europa) - começava a se constituir como agenda permanente de debates entre os governos; entre os principais debates e atos específicos, cita-se a Carta Encíclica Rerum Novarum, do Papa Leão XIII, cujo documento papal contextualizava as condições do operariado; seria neste momento que a Igreja assumia uma conduta com vistas a suavizar os rigores do capitalismo; ou ainda, pela criação da Organização Internacional do Trabalho - OIT, estabelecida pela Conferência de Paz, logo após a Primeira Guerra Mundial.

No Brasil, estudos como os de Castro Gomes (Burguesia e Trabalho: política e legislação social no Brasil, 1917-1937) e Werneck Vianna (Liberalismo e sindicado no Brasil), dentre outros, destacam que, em momentos pré-1930, o operariado transforma-se num ator marginal, e deixa de ser sujeito central da sua história para ser marginalizado como objeto de um problema a ser tratado e contido pelo Estado. No entanto, no pós-1930, os operários passam a não ser necessariamente marginalizados, mas são colocados como atores centrais por parte das políticas

${ }^{28}$ Classe social no sentido de setores que vão ganhando identidades e demandas de interesses, que se formam enquanto grupo político de pressão. 
pensadas no Estado varguista, que colocaram a classe trabalhadora enquanto objeto de uma espécie de regulamentação conservadora, com a conquista de direitos mínimos.

Nessas condições, o Governo Provisório empreendera um programa de reformas tão radical quanto imprevisto. É nesta imprevisão que as resistências surgiram, principalmente com o tempo despendido sem que o Governo promovesse o retorno ao Estado constitucional.

A crise enfrentada pelo Governo Vargas podia ser:

[...] entendida como transição para o moderno e desencadeada pelas mudanças da economia, pelo surgimento de novos atores e dilemas sociais, é o cenário que espelha o rompimento do arco de alianças e a hierarquia das forças sociais basilares para a arquitetura política do período anterior. [...] A revolução de 30 e o governo provisório revelariam, por sua vez, o posicionamento das novas forças sociais em emergência e o padrão de ordenamento de um novo pacto de alianças. Podemos observar essa característica nas estratégias e na engenharia governamental adotadas por Getúlio, ancoradas no diálogo, cooptação e negociação entre os diversos setores da economia e da sociedade, bem como na transferência dos conflitos para a arena mediadora e metamórfica do Estado. ${ }^{29}$

Em meio ao pêndulo confronto/compromisso, o Governo Provisório conseguia estabelecer tanto no âmbito federal quanto estadual um Estado forte e centralizado, e concentrava as principais decisões de construção de uma ideologia de classe dos trabalhadores em torno das ações políticas e ideológicas do governo Vargas.

A atuação de Agamenon Magalhães foi enfática ao criar os "sindicatos de carimbo", eleger os membros da bancada dos representantes classistas e, assim, influenciar nos assuntos sindicais e trabalhistas do país. Enquanto isso, os sindicatos verdadeiramente defensores dos reais interesses dos trabalhadores, sob orientação de lideranças de esquerda, tinham suas sedes destruídas e seus membros submetidos a espancamentos e prisões devido a intervenção da força policial. Com as ações populares organizadas pela ANL (Aliança Nacional Libertadora), aumentou-se a repressão vinda do Ministério do Trabalho em articulação com a Força Policial, o que culminou no afastamento e na liquidação das lideranças sindicais de esquerda.

Esta tensão entre as forças em disputa no período produziu condições fecundas à elaboração de um projeto político que visava criar o problema da segurança nacional. Este projeto político afirmava a ameaça comunista e elaborava, por conseguinte, a solução com o

${ }^{29}$ CEPÊDA, Vera Alves. Contexto político e a crítica a democracia liberal: a proposta de representação classista na Constituinte de 1934. In: MOTA, Carlos Guilherme; SALINAS, Natasha S. C. Os juristas na formação do Estado-nação brasileiro. São Paulo: Saraiva, 2010, p. 196. 
Plano Cohen produzido pelas Forças Armadas que o apresentava como sendo responsável pela sublevação comunista iminente que, em tese, ameaçava a ordem política nacional.

O projeto político em questão fora elaborado tendo em vista o encaminhamento do golpe de 1937, que marcou um período de implacável repressão estatal e policial que tornara impossível a manutenção de qualquer tipo de resistência dos setores de esquerda da classe trabalhadora. Nesse projeto, o direito de greve exerceu um relevante ponto de inflexão para uma melhor compreensão entre a relação Estado-sociedade. Embora o direito de greve tenha sido criminalizado pelo Estado Novo, considerado pelos agentes de Estado como uma medida anti-social, as restrições ao exercício daquele direito já eram observadas desde o início do governo provisório de Vargas. Nos debates constituintes de 1933-34, o tema greve já era objeto de disputa entre os setores ligados ao capital e trabalho. Mesmo que ausente na Constituição de 1934, o direito à greve já estava “criminalizado” desde a promulgação da Lei de Segurança Nacional de 1935, radicalizando-se a partir da intentona comunista de novembro do mesmo ano.

No arquivo do Conselho Nacional do Trabalho junto ao Tribunal Superior do Trabalho em Brasília, é possível observar como reclamações trabalhistas ${ }^{30}$ decorrentes de greve eram violentamnte tratadas pelos conselheiros de classe vinculados ao governo varguista e seu principal ministro do trabalho: Agamenon Magalhães.

De acordo com Castro Gomes, ${ }^{31}$ o papel assumido por Agamenon Magalhães possuía o seguinte propósito político nos primeiros anos do Governo Vargas (1930-1937):

\begin{abstract}
A escolha de Agamenon Magalhães para a pasta do Trabalho teve, portanto, um amplo sentido. A partir de então não mais haveria competição entre propostas concorrentes, nem lutas nos sindicatos ou nas ruas. A repressão ao comunismo tornaria inviável qualquer tipo de ação independente surgida do interior da classe trabalhadora. Um longo silêncio teve início em 1935, reforçando-se em 1937 e perdurando praticamente até $1942 .^{32}$
\end{abstract}

No bojo desta nova situação política marcada pela necessidade de reorientação nos rumos do Estado Novo, que o projeto "trabalhista” passou a ser difundido e implementado. A articulação deste projeto político contou com a importante nomeação e atuação em 1941 de

\footnotetext{
30 No arquivo do Conselho Nacional do Trabalho é possível constatar 972 processos entre 1923-1945. Disponíveis para consulta, os processos retratam o rigor exercido pelo governo após 1935. Esse rigor reflete não apenas violações de direitos aos trabalhadores, mas dava o tom de como a repressão aos movimentos paredistas (de greve) passaram a ser considerados como ações anti-sociais à organização do trabalho.

${ }^{31}$ GOMES, Angela Maria de Castro. A invenção do trabalhismo. São Paulo: Vértice/IUPERJ, 1988.

32 Ibid., p. 192.
} 
Alexandre Marcondes Filho na pasta do Ministério do Trabalho, Indústria e Comércio. Sua ação política no campo da sindicalização produziu uma nova lei de caráter corporativo, em que, ao adaptar as organizações sindicais a este princípio corporativista, coroou a política trabalhista com a instituição da Justiça do Trabalho e desenvolveu a atuação ministerial na área previdenciária.

Além da regulamentação do mundo do trabalho e dos direitos materiais e jurídicos, o Governo Vargas, neste segundo movimento pós-1940, conseguiu unir esta lógica material de custo/benefício com uma lógica simbólica. O Estado apropriou-se dos elementos-chaves da autoimagem dos trabalhadores construída ao longo da Primeira República, ressignificando esta “palavra operária” em outro contexto. Conseguiu, desta forma, consolidar um pacto junto à classe operária e, também, uma ideologia: a ideologia "trabalhista".

Neste segundo movimento, importa assinalar que, em fins dos anos 1920, existia entre a classe trabalhadora no Brasil, disseminada por diferentes apelos políticos, toda uma ética valorativa do trabalho e do trabalhador, toda uma prática de relacionamento e toda uma experiência de organização em partidos políticos e sindicatos. Ao término da Primeira República, as lutas dos próprios trabalhadores garantiam-lhes uma figura de operário.

O ponto fundamental, porém, para o qual é necessário atentar é o da dinâmica de construção deste projeto de identidade operária desenvolvida pelo Estado. Apesar de não mencionar nos seus discursos amplamente divulgados pelo Departamento de Imprensa e Propaganda (DIP) as lutas dos trabalhadores antes de 1930, o Estado varguista faz uso desses valores antigos, já presentes na mentalidade desses operários, para inventar a ideologia trabalhista e, assim, constituir uma identidade e cultura política da classe operária brasileira.

Neste sentido, portanto, há uma importante diferença e diversas especificidades que distinguem os processos de formação da Classe Operária Inglesa descrita por Thompson, ${ }^{33}$ quando comparado com a formação da Classe Operária Brasileira apresentada por Castro Gomes. ${ }^{34}$

No caso inglês, a formação da cultura política da classe operária foi o resultado das experiências de um processo histórico de vinte e cinco anos, contando com massiva propaganda da imprensa radical que utilizava a prensa gráfica em prol dos interesses da classe trabalhadora.

\footnotetext{
33 THOMPSON, Edward Palmer. A formação da classe operária inglesa. 3. Volume. Rio de Janeiro: Paz e terra, 1987.

${ }^{34}$ GOMES, Angela Maria de Castro. A invenção do trabalhismo. São Paulo: Vértice/IUPERJ, 1988.
} 
Este processo de lutas resultou na elaboração de uma consciência de classe para si articulada pelos próprios trabalhadores, na qual reconheciam-se como membros pertencentes a uma classe em detrimento do Estado, cujos seus interesses eram antagônicos.

Já no caso brasileiro, a palavra "operária” foi conduzida de forma difusa pelos próprios trabalhadores na Primeira República, até meados dos anos 1930, período no qual o Estado Novo promoveu por meio de várias ações o desmantelamento das organizações de classe dos trabalhadores (1934-1942) e a constituição de sua identidade de classe enquanto ideologia trabalhista. Com a impossibilidade de rearticulação das instituições de classes, pelos próprios trabalhadores, devido ao contexto e circunstâncias políticas, a partir de 1942, o Estado passou a conduzir a identidade de classe dos trabalhadores através da invenção da ideologia trabalhista. Promoveu um pacto político entre essas esferas sociais que, no caso do Brasil, podem ser vistas como contraditórias, e não antagônicas como foi no caso britânico. Este pacto político pode ser observado nas esferas político-legislativas como expressão das articulações do Estado varguista em prol da construção da "cidadania regulada" estendida aos membros da classe trabalhadora.

\section{CONCLUSÃO}

Ao analisar o campo das correlações de força existentes nas disputas políticas em torno da busca por direitos, as pressões históricas de organizações políticas dos segmentos expressivos da sociedade civil, como os movimentos dos trabalhadores, foram levadas em consideração. Os trabalhadores buscaram construir suas identidades operárias durante as primeiras décadas do século XX, ao mesmo tempo em que se apropriavam do espaço político para se colocarem no centro da política brasileira. Sob a perspectiva da história do direito, a reconstrução historiográfica desses momentos constitucionais é fundamental para uma melhor compreensão de como espaços de experiência (políticos, trabalhistas, econômicos, entre outros) se constituíram à época em que um horizonte de expectativas se formalizava.

No entanto, muitas das conquistas constitucionais no campo de direitos foram concomitantes às articulações políticas por parte da esfera estatal que resultaram na construção de uma cidadania restringida, com baixa representatividade, permeada por aspectos ideológicos do projeto político do Estado Novo.

Neste sentido, os direitos de cidadania da maior parte da sociedade - a classe trabalhadora - ficaram restritos aos direitos sociais que correspondiam ao direito de trabalho, 
carteira de trabalho assinada e às promessas por educação, saúde, desporto e lazer, entre outros, "tutelados", em grande parte, pelas instituições estatais do Estado Varguista; por outro lado, limitava os direitos políticos de manifestação e de se representarem e serem representados mediante escolha de candidatos que emergissem do seio da classe trabalhadora.

A diretiva do Estado Novo foi a de criar os representantes operários por meio de sindicatos tutelados pelo Estado, o que se dizia “sindicato pelego", responsável por desmobilizar os segmentos de esquerda e as organizações operárias mais combativas que se articulavam contra a classe dominante e o projeto de Estado pós-1930.

Deste modo, para se ter direitos sociais era necessário que os trabalhadores abrissem mão dos seus direitos políticos, associando-se às entidades sindicais compostas por líderes "pelegos" que diziam representar os interesses dos trabalhadores ao garantirem a constitucionalidade dos direitos trabalhistas, que era uma velha reivindicação dos trabalhadores. No entanto, esses sindicalistas atrelados ao Estado constituíam peças-chaves do projeto político varguista centrado em torno do poder de dominação da ideologia "trabalhista".

O governo Vargas, levando em consideração as pressões e reivindicações históricas dos trabalhadores, articulou um sagaz projeto político para a solução de conflitos e estabelecimento de acordos que exerceu o poder ideológico na massa de trabalhadores, capaz de tomar para si a "palavra operária" e conduzir, no período do Estado Novo, o desmantelamento das organizações de classe dos trabalhadores (1934-1942).

A partir de 1942, o Estado passou a conduzir a identidade de classe dos trabalhadores por meio da invenção da ideologia trabalhista, o que caracteriza um pacto político entre Estado e trabalhadores, no qual o Estado toma as rédeas das reivindicações operárias enquanto sujeito histórico representante dos interesses dos trabalhadores.

Esse processo político desembocou em uma representação restrita dos trabalhadores que, neste momento, passou a ter baixa representatividade por seus interesses enquanto classe por conta de serem representados pelos interesses políticos do projeto varguista.

\section{REFERÊNCIAS}

AZEVEDO, J. A. M. de (Org.). Elaborando a Constituição Nacional: Atas da Subcomissão elaboradora do Anteprojeto 1932/1933. Edição fac-similar. Brasília: Senado Federal, 1993.

BENDIX, Reinhard. Construção Nacional e Cidadania. Tradução Mary Amazonas Leite de Barros. São Paulo: Edusp, 1996. 


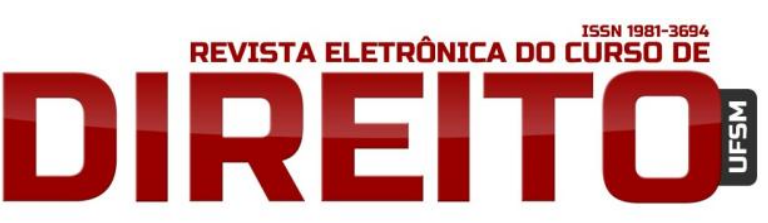

DIREITOS SOCIAIS E IDENTIDADE OPERÁRIA: O PODER DA IDEOLOGIA TRABALHISTA NO GOVERNO DE GETÚLIO VARGAS (BRASIL, 1930-45)

BERCOVICl, Gilberto. Constituição e Estado de exceção permanente: atualidade de Weimar. Rio de Janeiro: Azougue Editorial, 2004a. . Constituição e política: uma relação difícil. Lua Nova, São Paulo, n. 61, 2004b.

BICALHO, Maria Fernanda B.; GOUVÊA, Maria de Fátima S. (orgs.) Culturas Políticas: ensaios de história cultural, história política e ensino de história. Rio de Janeiro: Mauad, 2005.

BRASIL. Assembleia Nacional Constituinte (1933/1934). 22 volumes. Rio de Janeiro: Gráfica do Senado, 1935.

CABRAL, Rafael Lamera. Constituição e sociedade: uma análise sobre a (re)formulação na arquitetura do Estado-Nação na Assembleia Nacional Constituinte de 1933. Dissertação de mestrado em Ciência Política. São Carlos: UFSCar, 2010.

. Nos rastros de um processo: trabalho, conflito e uma experiência de micro-história. Tese de doutoramento em Direito. Brasília: UnB, 2016.

CARVALHO, José Murilo de. Cidadania no Brasil: o longo caminho. 10. ed. Rio de Janeiro: Civilização Brasileira, 2008.

CEPÊDA, Vera Alves. Contexto político e a crítica a democracia liberal: a proposta de representação classista na Constituinte de 1934. In: MOTA, Carlos Guilherme.; SALINAS, Natasha S. C. Os juristas na formação do Estado-nação brasileiro. São Paulo: Saraiva, 2010.

DOSSE, François. História e Ciências Sociais. Bauru: EDUSC, 2004.

GOMES, Angela Maria de Castro. A invenção do trabalhismo. São Paulo: Vértice/IUPERJ, 1988.

. Confronto e compromisso no processo de Constitucionalização (1930-1935). In:

FAUSTO, Boris. História Geral da Civilização Brasileira. Tomo III: O Brasil Republicano. São Paulo: Difel, 1990.

. História, historiografia e cultura política no Brasil: algumas reflexões. In: SOIHET, R., BICALHO, M. F. B.; GOUVÊA, M. F. S. (orgs.). Introdução. In: Culturas Políticas: ensaios de história cultural, história política e ensino de história. Rio de Janeiro: Mauad, 2005.

GUERRA, Maria Pia. Anarquistas, trabalhadores, estrangeiros: a construção do constitucionalismo brasileiro na primeira República. Dissertação de mestrado em Direito. Brasília: UnB, 2012.

HOBSBAWM, Eric. Mundos do Trabalho. São Paulo: Paz e Terra, 1988.

HOLANDA, Sérgio Buarque de. Raízes do Brasil. São Paulo: José Olimpio, 1976.

MARSHALL, Thomas Humphrey. Cidadania, classe social e status. Rio de Janeiro: Zahar, 1967. PULIDO, Carlos Bernal. O caráter fundamental dos direitos fundamentais. Revista de Direito do Estado, Rio de Janeiro, $\mathrm{n}^{\circ}$ 19-20: 17-35, jul./dez.2010. 




DIREITOS SOCIAIS E IDENTIDADE OPERÁRIA: O PODER DA IDEOLOGIA TRABALHISTA NO GOVERNO DE GETÚLIO VARGAS (BRASIL, 1930-45)

SILVA, Hélio. A lei e a revolta: 1934-1936. São Paulo: Editora Três, 1975.

SIMÃO, Azis. Sindicato e Estado: suas relações na formação do proletariado de São Paulo. São Paulo: Ática, 1981.

THOMPSON, Edward Palmer. A miséria da teoria ou um plenário de erros: uma crítica ao pensamento de Althusser. Rio de Janeiro: Zarar, 1981.

A formação da classe operária inglesa. 3. Volume. Rio de Janeiro: Paz e terra, 1987.

URBINA, Alberto Trueba. La primeira Constitución Social y Política del Mundo Moderno.

México: UNAM, 1971.

VIANA, Francisco José de Oliveira. Direito do trabalho e democracia social (o problema da incorporação do trabalhador no Estado). São Paulo: José Olympio, 1951.

. Problemas de direito corporativo. Rio de Janeiro: José Olympio Editora, 1938.

. O idealismo na Constituição. São Paulo: Editora Nacional, 1939.

VIANNA, Luís Werneck. Liberalismo e sindicato no Brasil. Rio de Janeiro: Paz e Terra, 1976.

WOLKMER, Antônio Carlos. Constitucionalismo e direitos sociais no Brasil. São Paulo: Acadêmica, 1989.

Recebido em: 26/05/2016 / Revisões requeridas em: 16/08/2016 /Aprovado em: 18/08/2016 